\title{
Spatial characteristics of precipitation shortfalls in the Greater Alpine Region-a data-based analysis from observations
}

\author{
Klaus Haslinger $^{1,2}$ (1) $\cdot$ Franz Holawe $^{3} \cdot$ Günter Blöschl ${ }^{2}$ \\ Received: 7 February 2017 / Accepted: 6 May 2018 / Published online: 30 May 2018 \\ (C) The Author(s) 2018
}

\begin{abstract}
In this paper, we investigate space time patterns of meteorological drought events in the Greater Alpine Region (GAR) of Europe. A long-term gridded dataset of monthly precipitation sums spanning the last 210 years is used to assess abnormally dry states using a shortfall below a monthly precipitation percentile threshold. These anomalies are calculated for 1, 3, 6, and 12 monthly moving averages. Contiguous areas of grid points below the threshold are indicating drought areas which are analyzed with respect to their drought severity. The severity is quantified by taking the average deviation from the threshold and the size of the drought area into account. The results indicate that the most severe dry anomalies in the GAR occurred in the 1860s, the 1850s, and the 1940s. However, no significant trends of dry anomaly severity are found over the last 210 years. A spatial clustering analysis of the detected drought areas shows distinct spatial patterns, with the Main Alpine Crest as a frequent divide between dryer areas in the north and wetter areas in the south, or vice versa. The patterns are highly significant and similar for all averaging time scales. The clusters are more clearly defined in winter than in summer. Droughts in the north are most frequent in the second half of the nineteenth century, while in the south and east, they are most frequent in the late twentieth century.
\end{abstract}

\section{Introduction}

From a first snapshot, the Greater Alpine Region (GAR; Auer et al. 2007) is a water-rich area, exhibiting annual precipitation totals from 400 to even beyond $3000 \mathrm{~mm} /$ year (Isotta et al. 2014). However, water scarcity is a serious issue in some parts of the area in some years which may cause substantial threats to drinking water supply, irrigation water supply, energy production (through cooling water and hydropower generation), and river navigation.

Within the last decades, several droughts struck large parts of Europe and the GAR (Spinoni et al. 2015; Hoerling et al. 2012; Parry et al. 2012; Bradford 2000; van der Schrier et al. 2006), e.g., the summer droughts of 2003 and 2015 as two of

Klaus Haslinger

klaus.haslinger@zamg.ac.at

1 Climate Research Department, Central Institute for Meteorology and Geodynamics (ZAMG), Hohe Warte 38, 1190 Vienna, Austria

2 Institute for Hydraulic and Water Resources Engineering, and Centre for Water Resource Systems, Vienna University of Technology, Karlsplatz 13, 1040 Vienna, Austria

3 Department of Geography and Regional Research, University of Vienna, Althanstraße 14, 1190 Vienna, Austria the most recent occurrences. They were caused by prolonged periods with below average precipitation which led, in combination with high temperatures, to severe drought related impacts (van Lanen et al. 2016; García-Herrera et al. 2010) not only in the GAR but also in large areas across Europe. However, not only in the warm season has an accumulated precipitation deficit has large impacts on society. In the Alps, winter sports are a major economic branch, depending heavily on sufficient snowfall in winter. A succession of three extremely dry winters in a row (1987/1988 to $1989 / 1990)$ substantially affected winter tourism (Abegg et al. 2007). Additionally, there is a close link between winter precipitation (e.g., via melt of the snow pack) and flow characteristics of rivers with a snow covered catchment during summer since insufficient snow pack might trigger low flows in the warm season downstream (Jenicek et al. 2016; Nester et al. 2012; Parajka and Blöschl 2008). Especially, a deficit of accumulated precipitation during winter may lead to low flow events of such rivers (Parajka et al. 2016).

Besides, any formal way to calculate any kind of indicator the term drought itself must be clarified. For example, Wilhite and Glantz (1985) discuss the issue of drought severity extensively and identify four types of drought: meteorological, agricultural, hydrological, and socioeconomic drought. Within this paper, we focus on meteorological droughts (precipitation 
deficit) as they trigger all other drought types (van Loon 2015; Stagge et al. 2015; Haslinger et al. 2014). Several studies have investigated long-term precipitation characteristics and change in the GAR, e.g., the studies of Brunetti et al. (2006, 2009) and Auer et al. (2005), who found increasing trends in precipitation north of the Alps and slightly decreasing trends south of the Alps from 1800 to 2003. These trends are connected to a dipole like feature of precipitation from north to south which strengthened somewhat over the past 200 years. Additionally, they reported a slight shift in precipitation seasonality with positive trends in winter and spring, counteracted by negative trends from July to November.

Brunetti et al. (2006) also analyzed spatial patterns of precipitation in the GAR, based on principal component analysis (PCA) of the precipitation time series. They found four homogeneous sub-regions in the GAR in terms of their inter-annual precipitation variability. The PCA of Brunetti et al. (2006) uses all the data of the probability distribution of precipitation; thus, those patterns for the dry tail of the distribution might look different. Van der Schrier et al. (2007) investigated soil moisture variability in the GAR, based on the self-calibrating Palmer Drought Severity Index (scPDSI; Wells et al. 2004). They used the previously defined sub-regions of Brunetti et al. (2006) regionalization to assess dry and wet episodes. Van der Schrier et al. (2007) left it open whether the predefined sub-regions are suitable for a dry episodes analysis.

Several studies investigated spatial and temporal patterns of drought occurrence globally or in other regions of the world. General assessments of drought characteristics and trends from global datasets are given for example in Sheffield and Wood (2008), Trenberth et al. (2014), or Dai (2011), highlighting regional differences in drought trends and large uncertainties considering the input data but on average increasing trends due to increased evapotranspiration. Spatial patterns of droughts on a global scale are investigated for example by Sheffield and Wood (2007) or Spinoni et al. (2014). Particular interest on spatial patterns on a regional scale was given by Soulé (1990) who analyzed various kinds of the Palmer Drought Severity Index through a PCA for the USA. The results showed more regions with smaller extent for faster responding indices (e.g., Palmer's Z-Index) and less individual regions with larger extent for slower reacting indices (e.g., Palmer Hydrological Index), which implies that the spatial characteristics are dependent on the time scale of the droughts. Similar results were found for the Iberian Peninsula by Vincente-Serrano (2006) who conducted an analogous analysis based on the Standardized Precipitation Index (SPI; McKee et al. 1993), comparing different accumulation time scales from 1 to 36 months. Other examples are the work of Cai et al. (2015) who performed a regionalization of drought characteristics based on a modified version of the Reconnaissance Drought
Index (RDI, Tsakiris and Vangelis 2005) for the BeijingTianjin-Hebei metropolitan areas and the work of Patel et al. (2007) who investigated spatial drought patterns based on the SPI in the region of Gujarat (India).

From the existing literature, no complete picture can be drawn on the spatial patterns of meteorological drought in the GAR. The most comprehensive work on drought in the GAR conducted by van der Schrier et al. (2007) did not analyze the spatial aspects of observed droughts. Consequently, an investigation of drought patterns in the GAR is still missing. Yet the GAR provides the possibility to investigate the spatial dimension of drought in a worldwide unique long-term (200+ years) assessment, enabling to investigate spatial patterns of droughts and changes of those over the last two centuries. Particularly, considering global climate change, it is of utterly importance to enhance our understanding of past droughts to better assess possible future developments. Stepping into these detected research gaps, we aim to analyze the long-term (200+ years) characteristics of drought patterns in the GAR. The more specific aims of the paper are (i) to detect areas under drought using accumulated precipitation on different time scales and to quantify the drought severity of the area, (ii) to assess similarities of these drought areas in order to obtain main drought patterns, and (iii) to investigate possible long-term changes of drought patterns over the past $200+$ years.

\section{Data}

The spatial domain of this investigation is the European Greater Alpine Region (GAR; Auer et al. 2007) which stretches from $4^{\circ}-19^{\circ} \mathrm{E}$ to $43^{\circ}-49^{\circ} \mathrm{N}$ (Fig. 1). The GAR is known for high-quality, long-term climate information back to 1760, the so-called HISTALP database (Böhm et al. 2009). In this paper, gridded data of monthly precipitation sums covering the whole GAR are used. This dataset was created by Efthymiadis et al. (2006) by gridding the available HISTALP stations with precipitation measurements, which are at maximum density nearly 200 stations. For the purpose of this paper, the dataset was updated until 2010 using similar techniques as for the original dataset described in the following section. The dataset therefore covers the period 18012010. It has a spatial resolution of $10^{\prime}$, which is roughly $15 \mathrm{~km}$.

The gridding is performed by the "anomaly approach" (e.g., Jones and Hulme 1996), which splits the precipitation field in two components. One is the long-term mean component, the climatology fields. Efthymiadis et al. (2006) used a high-resolution monthly precipitation climatology of the ETH Zürich (Schwarb 2000) from 1971 to 1990 which utilizes a very dense station network in order to capture the complex spatial features of precipitation in the GAR. The second component is the anomaly field. It is derived by interpolating 


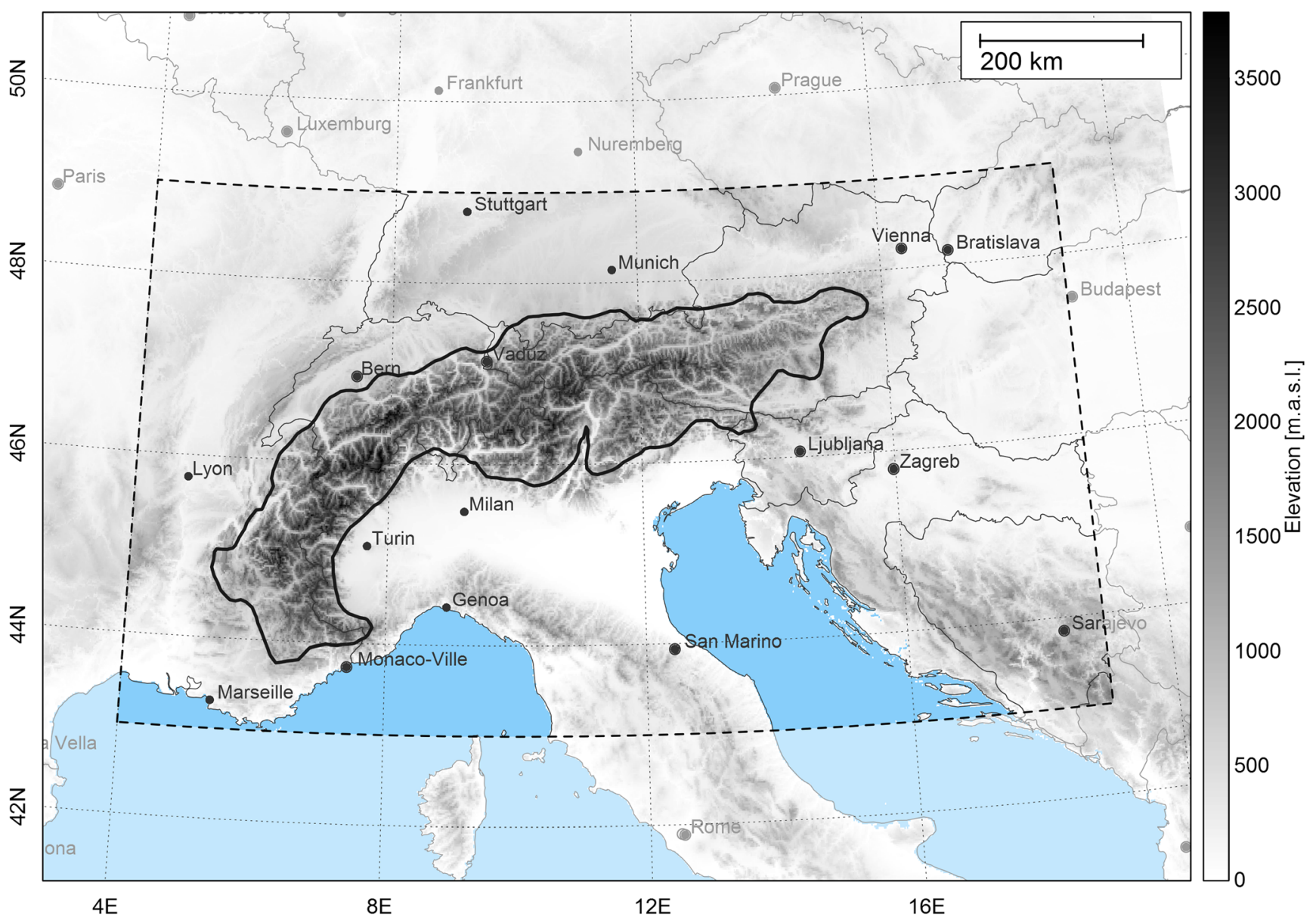

Fig. 1 Map of Central and Southern Europe. The broken line indicates the boundaries of the Greater Alpine Region; the solid line represents a generalized outline of the $1000 \mathrm{~m}$ a.s.l. isoline of the Alps which should help in locating the mountainous areas of the domain in the following figures

station anomalies relative to the averaging period of the climatology (1971-1990) using the angular distance weighting approach. The combination of the high-resolution climatology and the smoother anomaly fields yields the final absolute precipitation fields. However, it should be noted that only stations up to $2000 \mathrm{~m}$ a.s.l. are used; thus, uncertainties of the gridding in the high elevated areas of the GAR should be kept in mind.

In this paper, we use the gridded precipitation data to assess abnormally dry states in space which could subsequently lead to soil moisture, streamflow, or groundwater drought. To account for the different time scales on which these effects may arise, the precipitation values are summed up by a moving window approach over a 3-month $(3 \mathrm{M})$, a 6 -month $(6 \mathrm{M})$, and a 12-month $(12 \mathrm{M})$ time scale, similar to the procedure to calculate the Standardized Precipitation Index (SPI) on different accumulation time scales (see McKee et al. 1993).

\section{Methods}

Depending on the available data, different approaches have been used so far to depict drought (Zargar et al. 2011;
Mishra and Singh 2010; Heim 2002; Wilhite and Glantz 1985). During the last decades, especially three indices are in use for research and operational applications: the Palmer Drought Severity Index-PDSI (Palmer 1965), the Standardized Precipitation Index-SPI (McKee et al. 1993), and the Standardized Precipitation Evapotranspiration Index-SPEI (Vincente-Serrano et al. 2010). The SPI can be calculated from precipitation data alone; for the calculation of the PDSI and SPEI, potential evapotranspiration (PET) would be required. We intentionally do not use the PDSI or the SPEI, because (i) the incorporation of a temperature-based PET (other variables are not available for the GAR for this time period) introduces additional uncertainty (e.g., Sheffield et al. 2012) and (ii) we are interested in understanding the spatial patterns of precipitation deficit; investigating the climatic water balance would introduce more aspects and processes, e.g., landatmosphere interaction which might obscure the original intensions.

Instead of using the SPI, we use precipitation quantiles on four different accumulation time scales $(1,3,6$, and 12 months) to quantify meteorological drought conditions in the GAR. Quantiles introduce a lower boundary (zero), which 
makes a severity assessment, as described below, much more straightforward. As highlighted by Naresh Kumar et al. (2009), the SPI underestimated the severity of dry and wet extremes due to distribution fitting issues which underpins the advantage of using quantiles.

The procedure to identify dry areas is displayed in Fig. 2. Figure 2a shows an example of a precipitation field, the December of 1829. The spatial patterns of this field are characterized by low precipitation in the northwest of the domain, well below $50 \mathrm{~mm} /$ month. In contrast, in some coastal areas of Croatia, precipitation sums exceed $300 \mathrm{~mm} /$ month. In the same manner as for calculating the SPI, a Gamma-distribution (Wilks 2011) is fitted to the time series at every grid point. The parameters of the distribution are individually estimated for all the Januaries, Februaries, and so on and repeated for all three accumulation time scales. This procedure ensures comparability of anomalies across seasons, independent of the climatological mean of the precipitation sum.

From the estimated Gamma distribution, the precipitation values (e.g., for the example of 1829 in Fig. 2a) are assigned to percentile values (Fig. 2b). Obviously, regions in the northwest faced rather low values, well below the $10 \%$ percentile, indicating a relatively unusual month. As a next step, a threshold of the percentile values is determined to separate dry areas from non-dry areas. We chose the $20 \%$ percentile, which is a widely used threshold for drought identification (e.g., Svoboda et al. 2002). The threshold is indicated as a gray outline in Fig. 2b. As a next step, all spatially neighboring grid points below the threshold are aggregated to regions, which we term drought areas (DAs). In Fig. 2c, two identified DAs, A and B, of December 1829 are displayed. All key attributes of a detected DA are summarized by a lookup table covering the region ID, the grid point IDs, longitudes, latitudes, quantile values, and the month and year of occurrence. For further analysis throughout the paper, we use only DAs with a minimum size of $20 \%$ relative to the whole GAR.

For our study, the affected area of a drought by itself is an important drought measure. Therefore, we decided to define also the severity of a detected drought area by scaling the mean deviation from the threshold level by the number of affected grid points. The severity of a DA is given by Eq. (1).

$S=\sum_{i=1}^{n}(-1(q-t)) / t$

where $S$ is the severity which is a dimensionless measure; $n$ is the number of all grid points $i$, detected within a DA; and $q$ is the quantile value and $t$ the threshold (fixed at 0.2 ). This implies that the severity is higher, if either the DA or deviation from the threshold is large. Highest severities are given, if the DA as well as the threshold deviation is large.

In Fig. 3, examples of four individual DAs are displayed. Figure 3 a shows a meteorological drought on a $1 \mathrm{M}$ time scale in February 1814, affecting mostly the southern part of the GAR. The affected area is rather large, while the mean quantile value is rather low (0.077), resulting in a larger value of the overall severity of 982 . In contrast, the DA from February to April 1930 (M time scale; Fig. 3b) is considerably smaller, impacting mostly the western part of Austria. In combination with a mean quantile value of 0.125 , the severity is only 39 . However, this DA is not considered in the further analysis since it is below our chosen area threshold (20\% of the GAR). Another example with large spatial extent, but low mean quantile deviation from the threshold is displayed in Fig. 3c. This DA on a $6 \mathrm{M}$ time scale (May-October 1822) covers large areas in the east, but the mean quantile value is 0.141 , yielding a severity of 299 , which is considerably lower than the severity of February 1814 (Fig. 3a). A last example, for the $12 \mathrm{M}$ time scale, shows the DA from July 1954 to June 1955 in Fig. 3d. The spatial extent is not large, but the mean quantile value is low, which gives a severity of 258 , comparable to the severity in Fig. 3c, but affecting not nearly half of the area. Some guidance on the probability distribution of the severity is shown by Table 1 which displays the severity values associated with certain quantiles. In general, the severity is somewhat decreasing with higher accumulation time scale. The median ranges between 648 and 571, whereas the 95\% quantile lies between 1879 and 1621 . There is indeed a theoretical upper bound of the severity which relates to the size of the grid. If all the grid points would show no precipitation at all at a given time step, equivalent to a quantile value of zero, a)

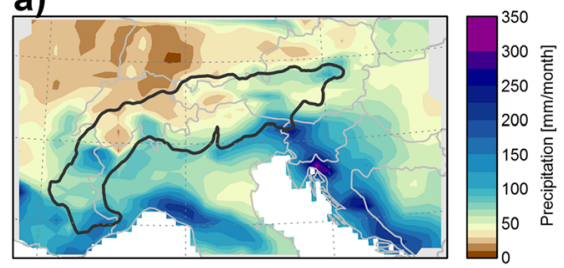

b)

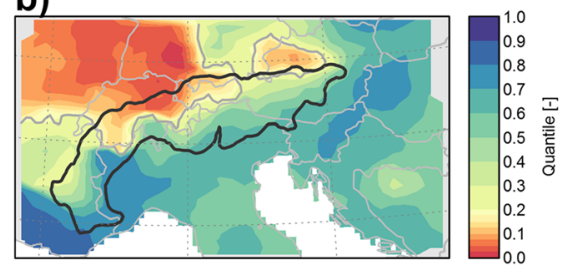

c)

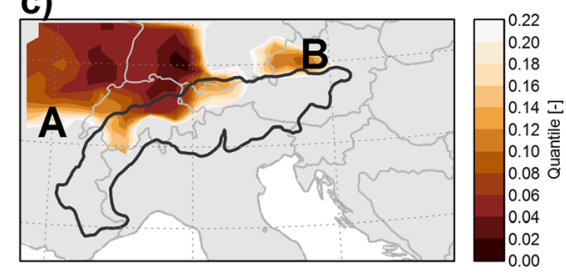

Fig. 2 Example of a precipitation field of December 1829 (a), the corresponding quantiles; the gray contour line represents the 20th percentile (b), and the detected contiguous drought areas for the selected date A and B (c) 
a)

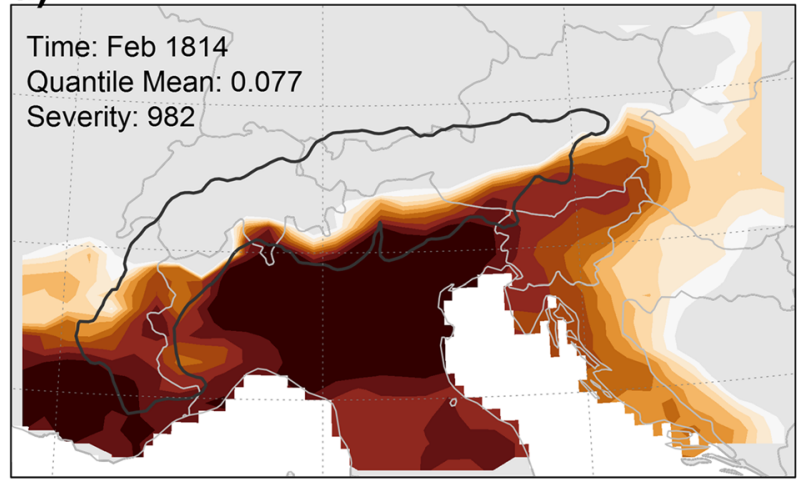

c)

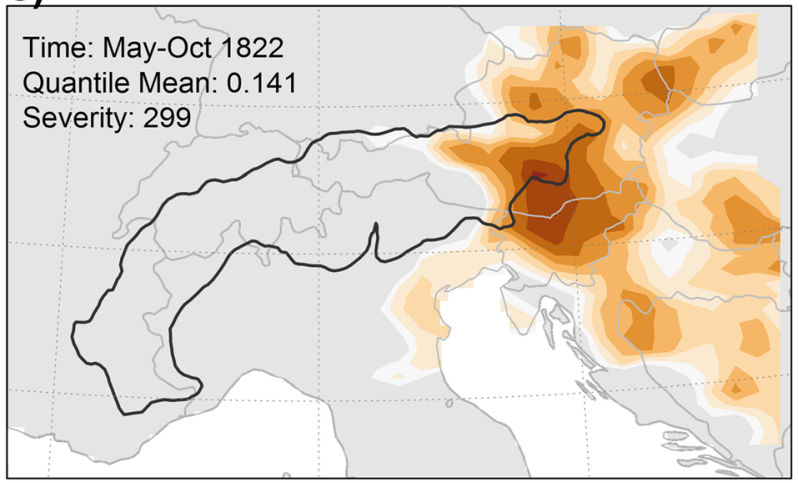

b)

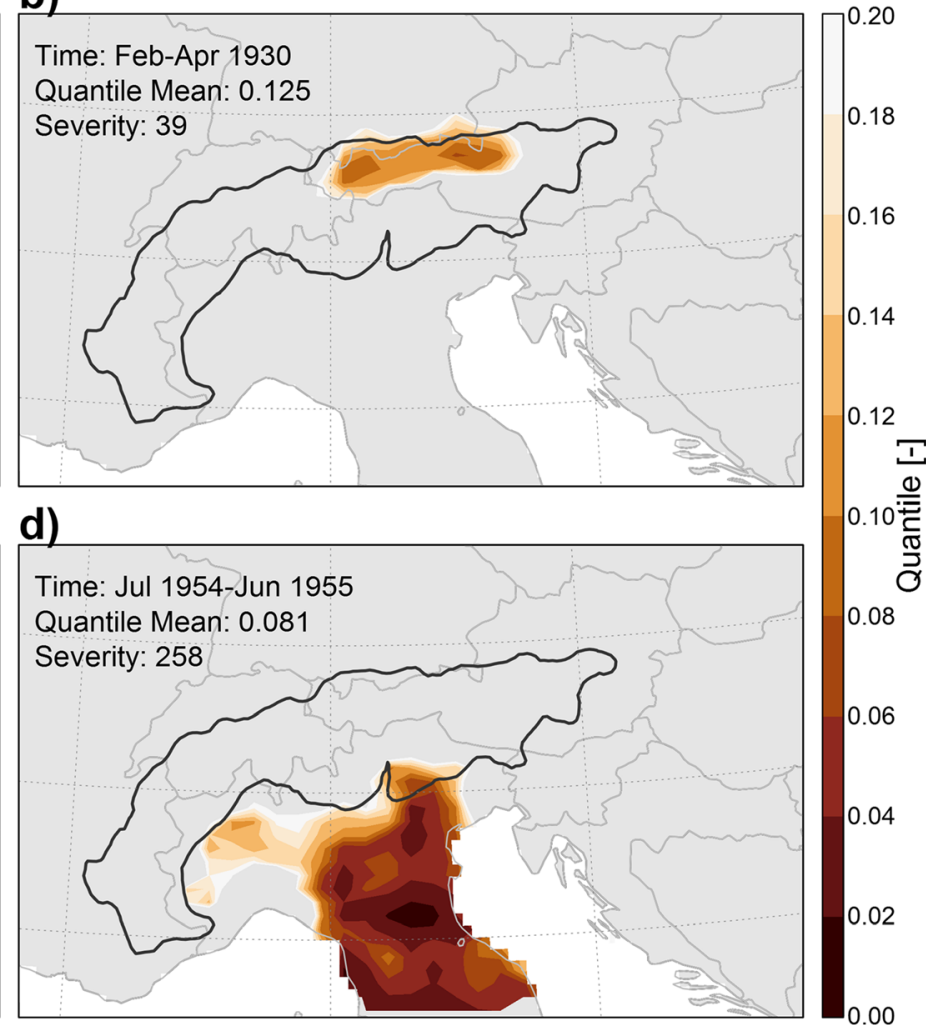

Fig. 3 Four examples of identified DAs on a 1-month (a), 3-month (b), 6-month (c), and 12-months (d) time scale. Every DA is described through three attributes exemplarily: the time period of occurrence (time), the quantile mean of the DA, and the severity

the severity would be 2895 , which is the number of all land surface grid points in the GAR.

The main methodological framework of this investigation is the clustering of spatial patterns of DAs in order to gain information on the spatial behavior of meteorological drought. We identify similarity patterns of DAs by a k-means clustering approach. We use the monthly DA-fields, where all grid points with percentile values outside the $0-0.2$ range are set to zero, in order to avoid biases arising from prominent wet features in space, and all grid points below the threshold boundary are set to one. Within the k-means approach, Euclidian distances (Wilks 2011) between data points are calculated, which are matrices with binary information on drought (one) and no drought (zero). The distances are iteratively minimized trough

Table 1 DA severity associated with different quantiles stratified by accumulation time scale

\begin{tabular}{|c|c|c|c|c|}
\hline \multirow[t]{2}{*}{ Quantile } & \multicolumn{4}{|l|}{ Severity } \\
\hline & 1 month & 3 months & 6 months & 12 months \\
\hline $50 \%$ & 648 & 604 & 583 & 571 \\
\hline $80 \%$ & 1160 & 1112 & 1040 & 960 \\
\hline $90 \%$ & 1557 & 1437 & 1335 & 1285 \\
\hline $95 \%$ & 1879 & 1699 & 1629 & 1621 \\
\hline
\end{tabular}

the sum-of-squares criterion for a previously defined number of clusters (Bishop 1995). The crucial part of the clustering algorithm is the determination of an optimal number of clusters. In this paper, we use the silhouette width approach (Rousseeuw 1987) which describes the similarity of an object to the assigned cluster as well as the dissimilarity to all other clusters. It ranges between -1 and +1 , with higher values indicating better clustering solutions. The significance and stability of a given clustering solution are assessed through the clustering stability (Hennig 2007) approach.

\section{Results}

\subsection{Drought areas and their severity}

Figure 4 shows the top 100 DAs in terms of their severity, stratified by the accumulation time scale. The DAs cluster around the middle of the 19th, as well as the twentieth century and in the 1890 s if only the $1 \mathrm{M}$ time scale is considered. On a $1 \mathrm{M}$ time scale, $13 \mathrm{DAs}$ of the topmost ones are detected in the 1860 s, 9 in the 1850s, and 8 in both the 1920s and 1940s. Decades with rather low numbers of extreme DAs are the 1820s (0 DAs) and the 1810s (1 DA), for example. Time periods of prolonged dry conditions are revealed considering 


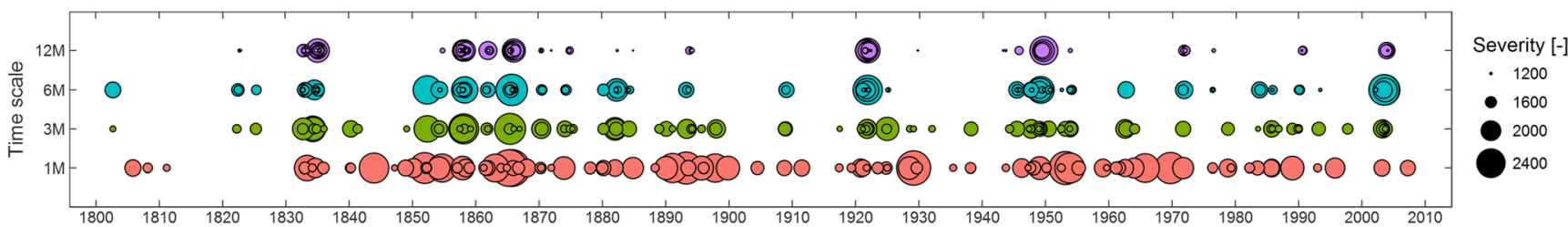

Fig. 4 Time of occurrence and magnitude of the top 100 drought areas (DAs) for the GAR described by their time scale ( $y$-axis and indicated by different color shadings) and by their severity (size of the symbols)

higher aggregation levels. On a $3 \mathrm{M}$ and $6 \mathrm{M}$ time scale, the 1940s show the highest DA occurrence (12 and 16 DAs respectively), followed by the 1920 s on a $3 \mathrm{M}$ time scale with 9 DAs and the 1860 s on a $6 \mathrm{M}$ time scale with 13 DAs. On a $12 \mathrm{M}$ time scale, the 1830s (20 DAs), 1850s (18 DAs), and the 1860s (17 DAs) are identified as periods of maximum drought occurrence.

It should be noted that, as an additional effect of using moving averages of the monthly precipitation sums in the time domain, DAs tend to cluster around similar years for different time scales. This is apparent mostly for the 12M line in Fig. 4. For example, the outstanding DA of October 1949 is surrounded by other, but smaller DAs along time.

The presented occurrence diagrams in Fig. 4 show a distinct decadal to multi-decadal scale variability of DA frequency. However, there is no apparent trend in the occurrence of droughts. We analyzed time series of annual averages of DA severity and frequency using the non-parametric MannKendall trend test for estimating the significance of the trend in the given time series. Since the accumulation procedure might introduce autocorrelation in the time series, these were prewhitened before significance assessment. As can be seen in Fig. 5, both the frequency and the severity show in general no significant trend, no matter what time scale is considered with $p$ values ranging between 0.11 and 0.48 .

Table 2 lists the top five DAs in terms of their severity per time scale. The overall driest month on record was September 1865, followed by April of the same year. This DA affected $99.5 \%$ of the whole GAR and shows an average precipitation anomaly of $-90 \mathrm{~mm}$ which equals $9 \%$ with respect to the longterm (1801-2010) mean. The overall deficit volume in this particular month is $61 \mathrm{~km}^{3}$ of water. The driest $3 \mathrm{M}$ period was April to June, again in 1865 . The area under dry conditions covers $98.4 \%$ and the overall precipitation anomaly is $-144 \mathrm{~mm}$, resulting in a deficit volume of $97 \mathrm{~km}^{3}$. The second and third driest $3 \mathrm{M}$ periods occurred in winter $1857 / 1858$, with similar precipitation anomalies of -139 and $-152 \mathrm{~mm}$ respectively.
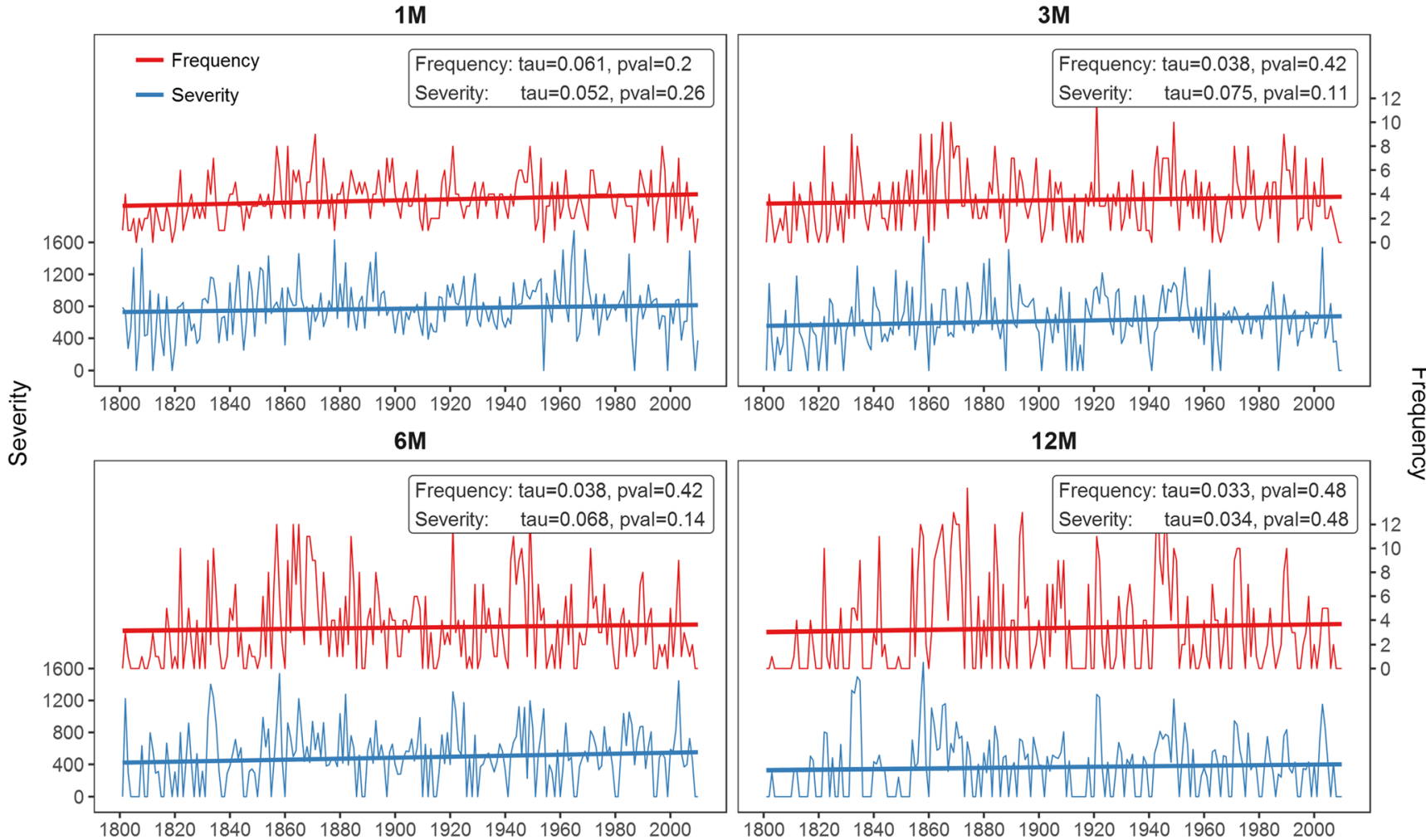

Fig. 5 Time series of annual averages of DA severity (blue) and annual frequency of DAs (red) stratified by accumulation time scale and the estimated trend line; respective values of Kendall's $\tau$ and the significance of the trend given by the $p$ value are given in the upper right corner 
Table 2 Characteristics of the top five drought areas (DAs) per accumulation time scale

\begin{tabular}{|c|c|c|c|c|c|c|c|}
\hline Time scale & Time period & $\begin{array}{l}\text { Severity } \\
(-)\end{array}$ & $\begin{array}{l}\text { Affected area } \\
(\%)\end{array}$ & $\begin{array}{l}\text { Mean percentile value } \\
(-)\end{array}$ & $\begin{array}{l}\text { Absolute anomaly } \\
(\mathrm{mm})\end{array}$ & $\begin{array}{l}\text { Relative anomaly } \\
(\%)\end{array}$ & $\begin{array}{l}\text { Deficit volume } \\
\left(\mathrm{km}^{3}\right)\end{array}$ \\
\hline \multirow[t]{5}{*}{1 month } & September 1865 & 2782 & 99.5 & 0.007 & -90 & 9 & 61 \\
\hline & April 1865 & 2765 & 100.0 & 0.009 & -73 & 14 & 50 \\
\hline & March 1929 & 2663 & 100.0 & 0.016 & -61 & 14 & 42 \\
\hline & March 1953 & 2602 & 97.7 & 0.016 & -63 & 12 & 42 \\
\hline & April 1893 & 2556 & 96.0 & 0.016 & -71 & 16 & 46 \\
\hline \multirow[t]{5}{*}{3 months } & April-June 1865 & 2520 & 98.4 & 0.023 & -144 & 50 & 97 \\
\hline & December 1857-February 1858 & 2477 & 97.2 & 0.024 & -139 & 36 & 93 \\
\hline & November 1857-January 1858 & 2342 & 98.0 & 0.035 & -152 & 41 & 102 \\
\hline & March-May 1852 & 2315 & 100.0 & 0.040 & -119 & 53 & 82 \\
\hline & February-April1834 & 2278 & 99.6 & 0.042 & -121 & 45 & 83 \\
\hline \multirow[t]{5}{*}{6 months } & April-September 1865 & 2546 & 99.4 & 0.023 & -232 & 60 & 158 \\
\hline & February-July 2003 & 2505 & 99.4 & 0.026 & -214 & 59 & 146 \\
\hline & March-August 2003 & 2504 & 97.8 & 0.023 & -219 & 60 & 148 \\
\hline & July-December 1921 & 2449 & 99.0 & 0.029 & -264 & 55 & 180 \\
\hline & December 1851-May 1852 & 2403 & 100.0 & 0.034 & -206 & 56 & 142 \\
\hline \multirow[t]{5}{*}{12 months } & November 1948-October 1949 & 2389 & 98.7 & 0.022 & -376 & 65 & 240 \\
\hline & January-December 1921 & 2229 & 90.1 & 0.029 & -389 & 64 & 241 \\
\hline & February $1852-$ January 1835 & 2174 & 92.1 & 0.037 & -347 & 68 & 220 \\
\hline & February 1865-January 1866 & 2156 & 91.4 & 0.037 & -325 & 70 & 204 \\
\hline & November 1920-October 1921 & 2107 & 90.4 & 0.039 & -347 & 68 & 216 \\
\hline
\end{tabular}

Also, on a $6 \mathrm{M}$ time scale, the year of 1865 reaches the top position with the period from April to September. Within these 6 months, only $60 \%$ of average precipitation was observed, resulting in a deficit volume of $158 \mathrm{~km}^{3}$. On ranks two and three, a more recent event is recorded, namely the time from February to August 2003, with a deficit volume of nearly $150 \mathrm{~km}^{3}$. Considering a $12 \mathrm{M}$ time scale, the driest period occurred from November 1948 to October 1949, followed by the time from January to December in 1921. Both show similar deficit volumes of 240 and $241 \mathrm{~km}^{3}$, respectively.

Considering drought occurrence stratified by seasons, somewhat different patterns are observed as can be seen in Fig. 6. We defined the cold season (warm season) as the half year spanning October to March - ONDJFM (April to SeptemberAMJJAS). In addition, we considered the core season within these half years: winter (DJF) and summer (JJA). DAs in the cold season are clearly more likely in the second half of the nineteenth century, although the biggest event on a $1 \mathrm{M}$ time scale occurred in March 1929 and on a 6M time scale in March 1949. The decades with the highest number of DAs in the cold season are the 1850 s on a $1 \mathrm{M}$ time scale $(6 \mathrm{DAs})$, the 1880 s on a $3 \mathrm{M}$ time scale (7 DAs), and the $1850 \mathrm{~s}, 1880 \mathrm{~s}, 1890 \mathrm{~s}$, and 1970 s on a $6 \mathrm{M}$ time scale. The warm season experiences most DAs in the 1940 s on a $1 \mathrm{M}$ time scale (7 DAs), in the 1920 s on a $3 \mathrm{M}$ time scale (9 DAs) and in the 1860 s on a $6 \mathrm{M}$ time scale $(8$ DAs). Considering the core season winter and summer, the patterns are similar. In winter (DJF), DAs are most frequent in the 1850 s and 1860 s on a $1 \mathrm{M}$ time scale (6 DAs) and in the 1850 s on a $3 \mathrm{M}$ time scale (6 DAs). In summer (JJA), the 1850s and 1940s show highest frequency of DAs on a 1M time scale (6 DAs), whereas the 1860s, 1920s, and 1940s show the highest number of DAs on a $3 \mathrm{M}$ time scale (5 DAs).

\subsection{Spatial patterns}

In this section, the spatial patterns of DAs are analyzed using a k-means clustering approach. The aim is to allocate every detected DA (c.f. Fig. 3) to a cluster of DAs with similar spatial properties. The result of the k-means clustering is a flag for the DAs indicating their spatial affiliation, e.g., all DAs covering the northwest of the GAR are assigned to the same cluster.

As described in Section 3, the optimal number of clusters has to be defined beforehand, which is carried out with the silhouette width approach (Rousseeuw 1987).

Figure 7 shows the silhouette width of different clustering solutions stratified by different time scales. First of all, silhouette widths of the clustering on different time scales are rather similar. If averaged over all time scales, the peak is at four clusters with silhouette widths of 0.30 for the $1 \mathrm{M}, 3 \mathrm{M}$, and $6 \mathrm{M}$ time scales and 0.25 for the $12 \mathrm{M}$ time scale (c.f. Table 3 ), indicating optimal clustering with four clusters. These values can be interpreted, following Kaufmann and Rousseeuw (2005), as "weak 

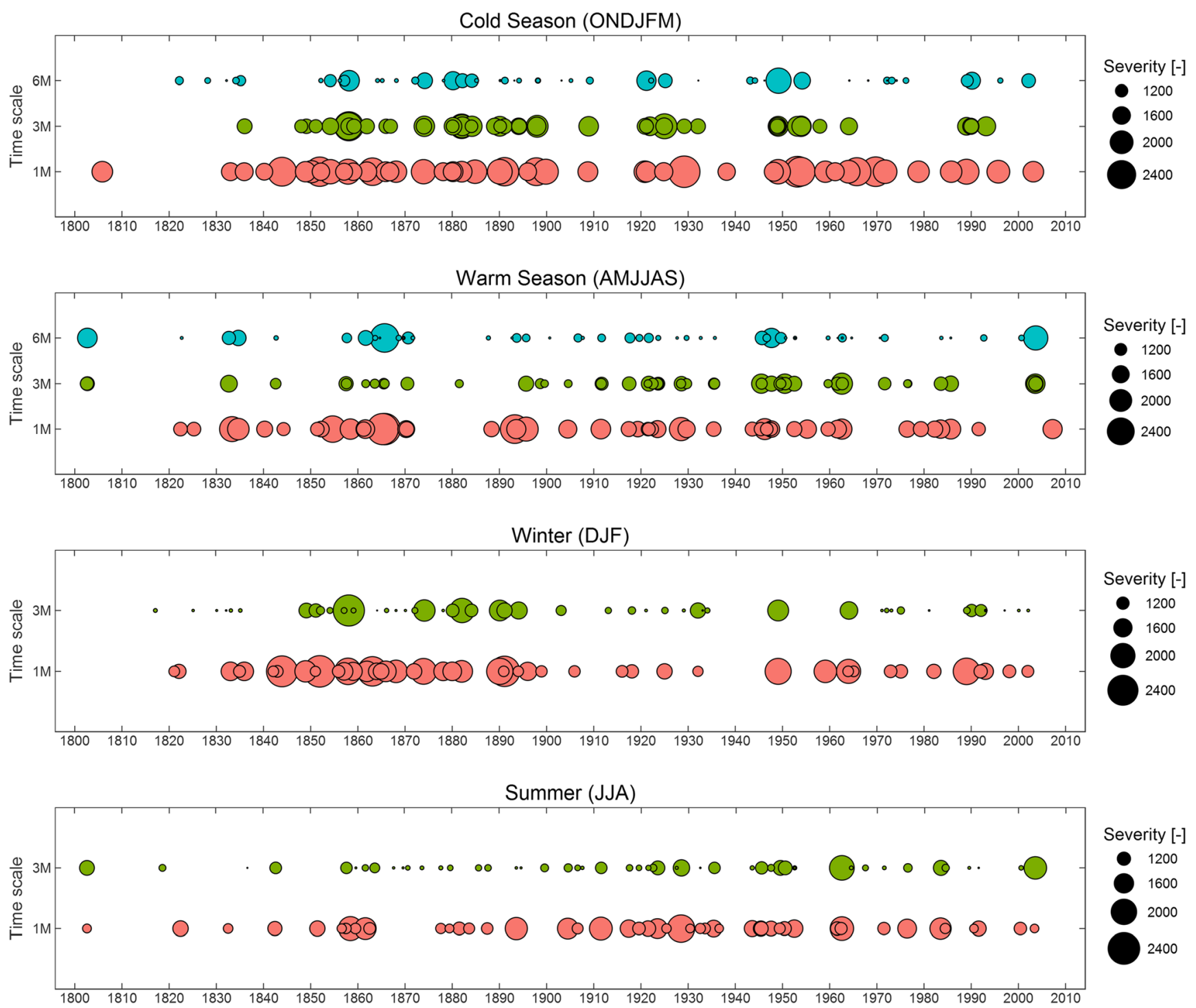

Fig. 6 Time of occurrence and magnitude of the top 50 drought areas (DAs) at different time scales (indicated by different color shadings) stratified by season. The two top most panels show the DAs in the halfyears (cold season ONDJFM and warm season AMJJAS); the two bottom most panels show the DAs in seasons (winter DJF and summer JJA). The attribution of a DA to a distinct season follows strictly their defined boundaries, for example, 6M DAs in the cold season are only those detected in March, since the $6 \mathrm{M}$ time scale refers to the accumulation from October to March; for this reason, there are only three time scales displayed in the half-year plots and two time scales in the seasonal plots. The size of the circles indicates the severity of the event

interpreted as "highly stable" (Hennig 2007); here, we have only two clusters below this threshold, indicating that the clustering solution is highly stable and significant, although silhouette widths are low, given the fact that cluster objects tend to overlap to some degree.

The obtained clusters are termed after the region within the GAR they are mostly affecting: northwest, southwest, east, and a cluster termed all dry which contains DAs covering very large parts of the GAR. Figure 8 shows the clusters displayed as a fraction value which indicates how often grid points from a DA are assigned to a given cluster (e.g., northwest) in relation to the overall size of the cluster (e.g., how often DAs are assigned to cluster northwest in total). 


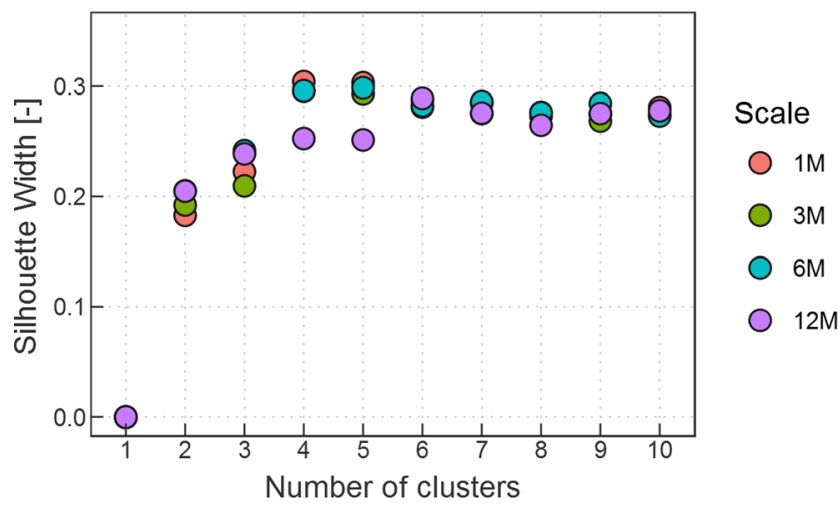

Fig. 7 Silhouette widths for different cluster solutions and different time scales of the DAs

The most striking feature of this figure is the similarity of spatial patterns independent of the accumulation time scale. All of these cluster composites show rather similar shapes and nearly identical locations of the center of mass. For example, the northwest cluster always shows highest fractions near the border triangle of France, Germany, and Switzerland, whereas the center of cluster southwest is located in the Po Plain. The cluster east tends to dominate the whole eastern half of the domain with a center in western Hungary. Moreover, the lower cluster stability at $12 \mathrm{M}$ time scale (cf. Table 3 ) is also reflected in the lower fraction gradient from north to south compared to the lower time scales $1 \mathrm{M}$ and $3 \mathrm{M}$. The remaining cluster is the all dry cluster, which indicates DAs where large parts of the domain are below the 20th percentile threshold. The similarity of cluster composites across time scales indicates that DAs are caused by persistent atmospheric circulation patterns leading to precipitation deficit in one of the three sub parts or the whole domain. Our choice of four clusters is based on the mean silhouette widths across all time scales. However, Fig. 7 also indicates that for a $12 \mathrm{M}$ time scale, compared to the other time scales, more clusters (six) would lead to slightly enhanced cluster results. Additional investigations of the patterns with six clusters on a $12 \mathrm{M}$ time scale (not shown) revealed consistent results, as two additional clusters emerge from a splitting of cluster northwest into a western and a eastern part and a splitting of cluster east into a northern and a southern part.

From the above analysis, it becomes clear that the Alps are a major divide between dry and wet conditions under certain

Table 3 Silhouette width and cluster stability of the k-means approach

\begin{tabular}{lllll}
\hline Time scale & 1 month & 3 months & 6 months & 12 months \\
\hline $\begin{array}{l}\text { Silhouette width [-] } \\
\text { Cluster stability [-] }\end{array}$ & 0.30 & 0.30 & 0.30 & 0.25 \\
Northwest & 0.95 & 0.96 & 0.86 & 0.89 \\
Southwest & 0.95 & 0.94 & 0.81 & 0.68 \\
East & 0.97 & 0.93 & 0.85 & 0.86 \\
All dry & 0.97 & 0.94 & 0.78 & 0.94 \\
\hline
\end{tabular}

circumstances. To underpin these results, we performed an additional analysis assessing the probability of change from dry to non-dry conditions in space. Therefore, all grid points identified as DAs per time step were flagged as 1 and all the others were flagged as zero. We then calculated the probability for the change in space from dry conditions (grid point value $=1$ ) to near normal or wet conditions (grid point value $=0$ ) between pairs of grid points in the north-south direction as well as in the west-east directions. The number of times a pair of grid points shows a $1 / 0$ (dry/non-dry or vice versa) combination is counted and related to the whole number of time steps. The result is a percentage probability for a change from dry to wet in one direction between pairs of grid points. The mean of these calculations for both directions (north-south, west-east) is displayed in Fig. 9.

The maps support the results from the k-means clustering, clearly showing a band along the main alpine crest with the highest change probabilities, which are somewhat larger at higher time scales. The change probabilities in space reach up to $6 \%$ along the main Alpine Ridge and some areas at the southern rim of the Alps where the mountainous terrain gives way to the PoPlain. The role of the Alps as a boundary of a north-south divide is rather clear, also seen in the k-means clustering results, but more restricted to the western part of the area. However, there is no similar boundary in a west-east direction. Although the clustering revealed an east cluster, the boundary is fuzzier and not as marked as for the north/south clusters. This fuzziness is also confirmed by the spatial change probability assessment, showing no clear areas with enhanced probability in a west/east direction.

In order to assess seasonal differences of spatial drought patterns, the clustering approach was carried out for winter (DJF) and summer (JJA) DAs separately, where we used a sub-sample of the 3M DAs detected in February (covering December through February) and in August (covering June through August). Following the silhouette width approach, the optimal number of clusters is 4 for winter and 2 for summer; cluster stability is again high with a mean value across clusters in winter of 0.72 and in summer of 0.84 .

In Fig. 10, the cluster composites for winter and summer are displayed. Winter shows some similarities with the all year cluster solutions: the first cluster dominates the north of the domain, again with a clear boundary along the Alpine crest; clusters two and three are more in the south and along the western and eastern fringe of the Alps. There is again an all dry cluster indicating widespread drought across the GAR. In summer, the characteristics of the patterns are different. In general, the two clusters show a northwest-southeast contrast too, but the region boundaries are rather fuzzy and the Alpine crest is not as clear a separating feature as in the all year analyses or in winter. This might be due to the different mechanisms of precipitation formation in summer which is usually a mixture of stratiform precipitation through cold and warm front passages and convective precipitation which is either triggered by frontal systems or generated locally. Therefore, 

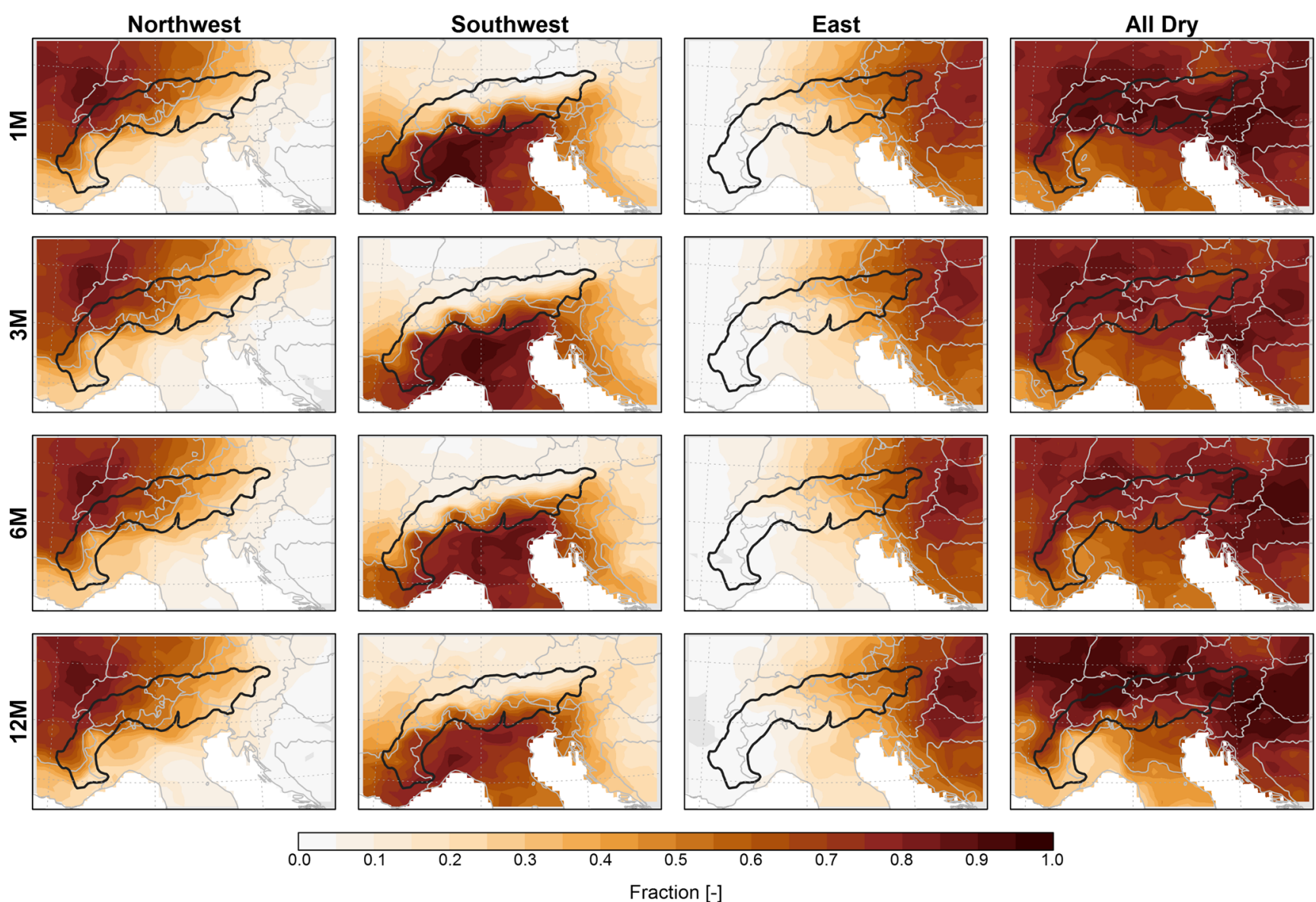

Fig. 8 Spatial patterns of DA clusters on different time scales. The fraction value indicates how often grid points from a DA are assigned to a given cluster (e.g., Northwest) in relation to the overall size of the

the precipitation patterns in summer on monthly or even multi-monthly averages tend to be more heterogeneous than those in other seasons with lower convective activity, resulting in fuzzier cluster boundaries.

\subsection{Spatial patterns in time}

The occurrence of the identified drought patterns in Section 4.2 varies over time. Temporal variations are apparent from the overall frequency of DA and also in the partitioning between clusters as can be seen in Fig. 11. On a 1M time scale, DA frequency is peaking in the period from 1860 to 1890 with an overall amount of about $130 \mathrm{DA} / 30$ years. The strong cluster (e.g., how often DAs are assigned to cluster northwest in total); higher fraction values indicate higher accordance of DAs assigned to the given cluster

increase of DAs at the beginning of the time series can be explained by decreasing precipitation sums following the very wet years within the first decades of the nineteenth century, with a rather low number of DAs. This pattern is also seen on longer accumulation time scales, but in addition, other characteristics emerge. Particularly, at the $6 \mathrm{M}$ and $12 \mathrm{M}$ time scales, two periods clearly stand out in terms of DA frequency, the time windows from 1850 to 1880 and from 1920 to 1950 , showing isolated peaks of $140-160 \mathrm{DA} / 30$ years.

The fraction of clusters for these 30 year periods is not homogeneous over time. As it was the case for the entire region's frequency, the differences in the frequency of the single clusters are more pronounced at longer time scales.
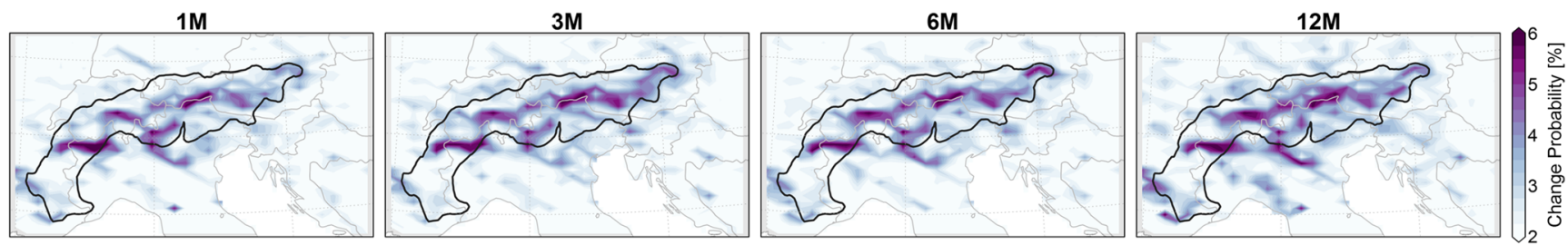

Fig. 9 Mean of the change probability between a pair of grid points within a DA and outside a DA in north-south and west-east directions on different accumulation time scales 


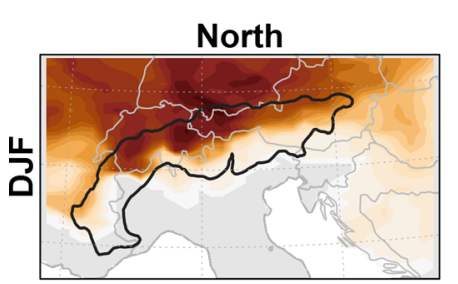

Northwest
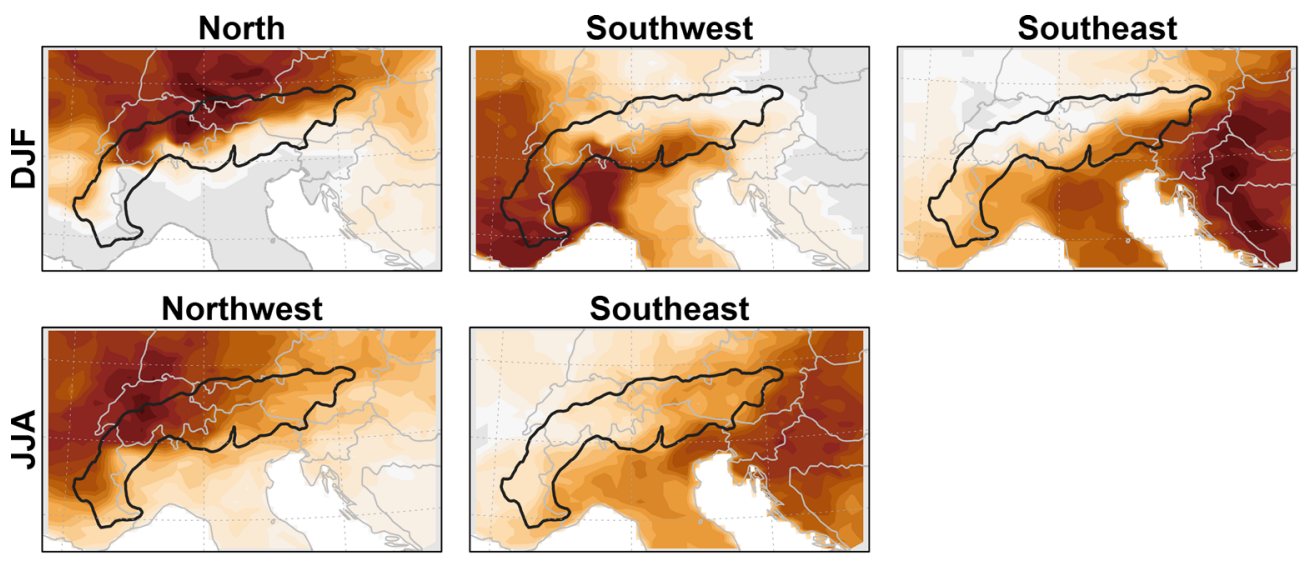

Southeast

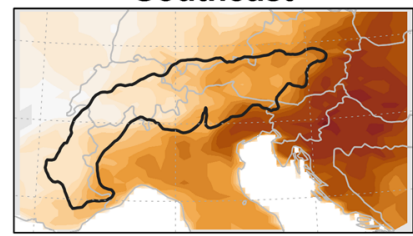

All Dry

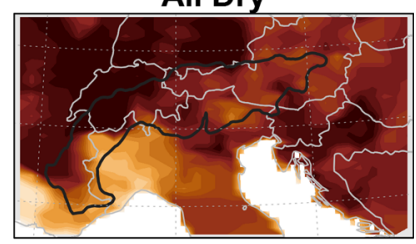

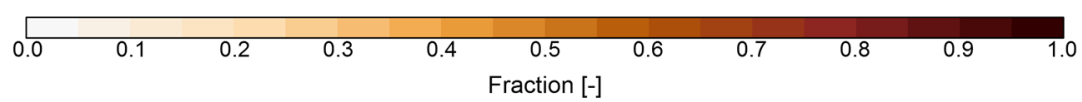

Fig. 10 Spatial patterns of clusters on a 3M time scale for winter (DJF) and summer (JJA). The fraction value indicates the number of cluster assignments of a grid point to a distinct cluster in relation to the overall

On the $12 \mathrm{M}$ time scale, there is no occurrence of DAs in the northwest region at the beginning of the nineteenth century. Afterwards, a steep increase is visible until the period from 1860 to 1890 showing, around 80 DAs/30 years. The northwest cluster is the one with highest temporal dynamics along with the east cluster. Both of them trigger the peaks in cluster frequencies in the middle of the nineteenth and twentieth centuries.

In terms of seasonal variability, the results are not as coherent as for the all year analyses. In Fig. 12, the relative cluster frequencies on a seasonal basis for winter and summer are shown. In winter, two pronounced peak periods are visible, one from 1851 to 1870 (16 DAs/30 years) and another from 1971 to 2000 (15 DAs/30 years). However, the two main peaks are different with respect to their cluster fraction. The peak in the nineteenth century is composed of the occurrence of all four clusters with the least contribution from the size of a cluster; higher fraction values indicate higher accordance of DAs assigned to the given cluster

southeast cluster, whereas the late twentieth century peak is dominated by the southeast cluster, and the all dry cluster is not at all present.

Less variation over time of DA frequency is visible in summer. After a steep increase during the beginning of the nineteenth century, the frequencies range between 9 and $12 \mathrm{DA} /$ 30 years. However, the small overall variation is counteracted by periodical changes of the cluster fractions. From 1851 to 1890 as well as from 1911 to 1960 , the southeast cluster is dominating, whereas in the other periods, the northwest cluster occurs more frequently.

\section{Discussion}

The analyses of this paper suggest that the time periods of the 1850 s through the 1870 s and the 1940 s were the driest in the
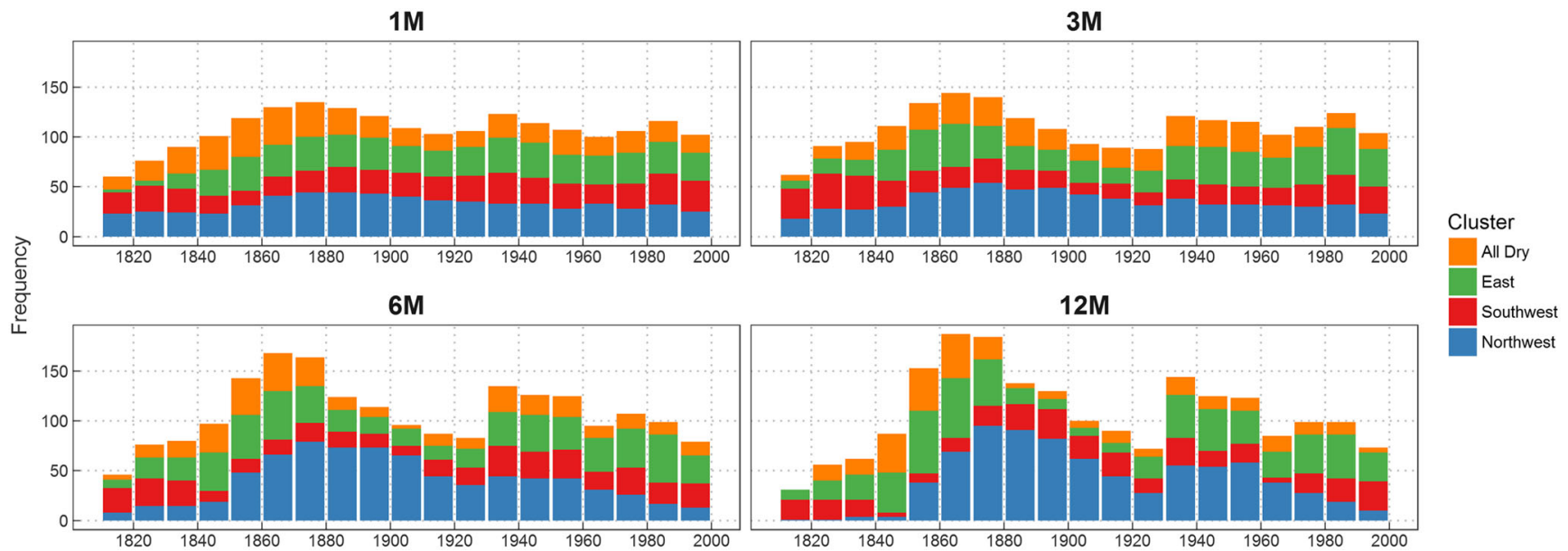

Fig. 11 Absolute frequency of clusters for 30-year periods at different accumulation time scales. Bars are centered at the given 30-year period, e.g., the first bar at 1815 represents the $1801-1830$ period 
DJF

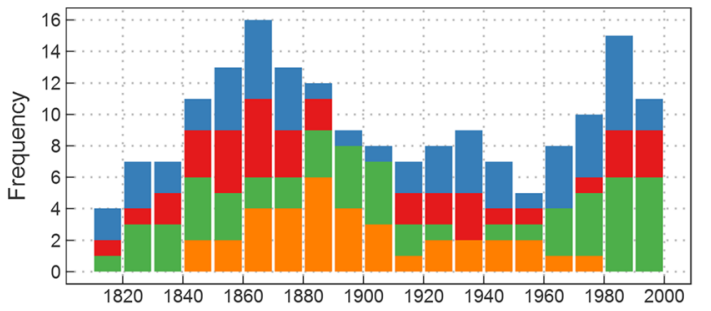

JJA

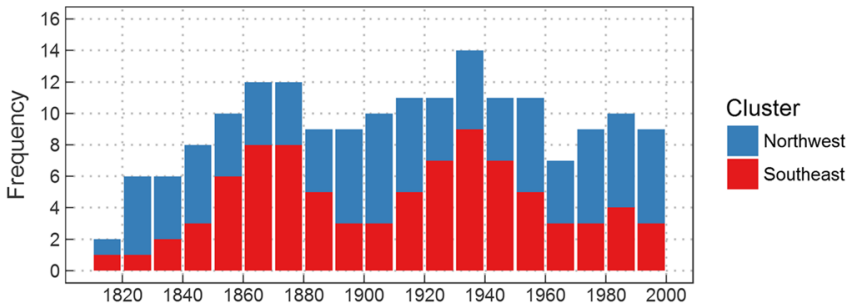

Fig. 12 Absolute seasonal frequency of clusters on a 3M time scale enveloping winter (DJF) and summer (JJA). Bars are centered at the given 30-year period, e.g., the first bar at 1815 represents the $1801-1830$ period

GAR during approx. the last 200 years. This result is in line with the findings of van der Schrier et al. (2007) who assessed the moisture variability based on the scPDSI. Particularly, the year 1865 clearly stands out in terms of severity of DAs. The associated DAs developed on different time scales (1M, 3M, and $6 \mathrm{M}$; c.f. Table 2) and led to severe drought impacts as some historical evidence shows (c.f. Soja et al. 2013). Interestingly, the year of 1865 is not known for severe drought impacts on agriculture. Although 1865 shows the most severe DA on a $6 \mathrm{M}$ time scale from April to September, it was the enveloping months April and September that were the most severest overall (c.f. Table 2). However, the aftermaths of these strong anomalies emerged later in winter. A historical Viennese report on January 1866 stated: "In Leopoldstadt (a part of Vienna) water scarcity is becoming noticeable. Many wells fell dry." And "Increasing water scarcity. The streambed of the Danube Channel is covered with thousands of dead fish." (BILkNÖ 1866; originally in German language, translation by the authors). But not only on a local scale was the severe dry anomaly noticeable. In a study by Pekarova et al. (2006), who investigated long-term streamflow trends across Europe, the authors found the 1860s and 1940s as outstanding dry periods for Western and Central European major river systems. Unfortunately, no north/south distinction among catchments has been carried out in their study. Investigations of more recent drought events in Europe show increasing dry and continental conditions during the last 20 years in the Carpathian Region (Spinoni et al. 2013) and also increasing drought conditions in the Balkans and Italy, whereas in Central Europe, no general trend is noticeable (Spinoni et al. 2015). The results of these papers underpin our results which show increased DA frequency in the southeast of the GAR, particularly in winter and no (1M and $3 \mathrm{M})$ or even decreasing (6M and $12 \mathrm{M}$ ) DA frequency in the northwest cluster during the second half of the twentieth century.

However, it is important to assess also the spatial characteristics of meteorological droughts in the GAR, since climate variability and precipitation regimes are rather diverse. Regional aspects have been considered, for example, in van der Schrier et al. (2007) who analyzed moisture variability in four different regions in the GAR. But the regionalization was based on the PCA of Auer et al. (2007) which treated all available climate variables of the HISTALP data base at once (temperature, precipitation, sunshine duration, cloudiness, and air pressure). As a consequence, this regionalization might not be useful for deriving homogenous drought regions. With our clustering approach, we were able to show that meteorological droughts tend to develop in three sub-regions and one region covering most of the domain. The results are partly consistent with the PCA of Auer et al. (2007), since our clusters northwest and southwest are to some extent comparable to regions northwest and southwest of Auer et al. (2007). However, cluster east is in our case not separated into a northern and a southern part as is the case in Auer et al. (2007), which is a fundamental difference. Interestingly, accumulating the precipitation on different time scales does not usually affect these patterns in contrast to investigations for, e.g., the Iberian Peninsula (Vincente-Serrano 2006).

These findings along with the change probability assessment in space from dry to non-dry states suggest that the Main Alpine Crest is a distinct boundary between different manifestations of the climate in the GAR. We found that the change probability from north to south for a dry to normal/wet condition is even enhanced if longer accumulation time scales are considered. This indicates that precipitation anomalies are persistent over several months, which may be related to reoccurring weather conditions, enhancing the spatial differences in anomalies. This dipole-like feature of precipitation in the GAR was initially detected by Böhm et al. (2003) and analyzed in more detail by Brunetti et al. (2006). They found that the north-south (N-S) dipole feature is more prominent than the west-east (W-E) feature, which is in line with the findings of our study. However, they also found an increasing trend in N-S dipole, which they attribute to negative precipitation trends in the southern part and mostly positive trends in northern parts of the GAR. This reflects our finding of dominating south and east clusters on higher accumulation time scales in the second half of the twentieth century.

With respect to seasonal aspects, the spatial patterns in winter (DJF) based on a $3 \mathrm{M}$ time scale are to some extent similar to the all year analyses indicating, again, a pronounced border along the Alpine Crest between dry and normal/wet conditions based on an optimal cluster solution of four clusters. For summer, however, this picture is not as clear. The 
quantitative assessment of an optimal clustering suggested two clusters to be the best following the silhouette width approach, resulting in a northwest and a southeast cluster. Furthermore, the cluster borders are much fuzzier and the Alpine Crest is not as strong a boundary as in the all year and winter clusters. The reason for this may lie in the dominance of convective precipitation which is either embedded in frontal systems or generated locally, producing heterogeneous spatial patterns of precipitation.

\section{Conclusions}

Considering the long-term perspective of more than 200 years of drought patterns in the GAR, we conclude that the time periods of the 1850s through the 1870s and the 1940s were the driest ones, as they showed both highest DA frequency and highest severities. The assessment of the similarity between DAs by the k-means clustering approach revealed three dominant sub-regions for drought occurrence which differ from the previous regionalizations of Auer et al. (2007), for example. We also conclude that the Main Alpine Ridge is a major climatic divide for droughts, which does apply not only to daily or monthly accumulation scales (c.f. Böhm et al. 2003) but also to multi-monthly time scales. The frequency of DA occurrence shows no trends, but rather exhibits multidecadal variations which are more pronounced at higher accumulation time scales. Interestingly, these also manifest differently for cluster regions, the north and west were more drought prone in the middle of the nineteenth century, whereas the east of the GAR shows higher DA frequency within the last decades. These findings indicate the importance of internal climate variability which seems to impact long-term spatial precipitation characteristics. This in turn implies that the general warming trend in the GAR (Auer et al. 2007) has either yet no detectable effect on drought patterns in space, or the processes involved are manifold, non-linear, seasonally dependent, and therefore not straightforward to analyze.

To better understand the processes driving the results of this paper, it is suggested to examine the circulation characteristics of the atmosphere during the occurrence of DAs. By investigating atmospheric features such as blockings, zonal and meridional wind patterns, and jet stream location, the atmospheric conditions leading to dry anomalies within the GAR should be explored and thus be better understood.

Acknowledgments The authors would also like to thank the Climate Research Unit of the University of East Anglia for hosting the Greater Alpine Region precipitation dataset. The paper is a contribution to UNESCO's FRIEND-Water program.

Funding information K. Haslinger is a recipient of a DOC fellowship (24147) of the Austrian Academy of Sciences which is gratefully acknowledged for financial support. Funding from the Austrian Science
Foundation as part of the Vienna Doctoral Programme on Water Resource Systems (DK Plus W1219-N22) is acknowledged.

Open Access This article is distributed under the terms of the Creative Commons Attribution 4.0 International License (http:// creativecommons.org/licenses/by/4.0/), which permits unrestricted use, distribution, and reproduction in any medium, provided you give appropriate credit to the original author(s) and the source, provide a link to the Creative Commons license, and indicate if changes were made.

\section{References}

Abegg BS, Jetté-Nantel S, Crick F, de Montfalcon A (2007) Climate change impacts and adaptation in winter tourism. In: Agrawala $S$ (ed) Climate change in the European Alps: adapting winter tourism and natural hazards management. OECD Publications, Paris

Auer I, Böhm R, Jurkovic A, Lipa W, Orlik A, Potzmann R, Schöner W, Ungersböck M, Matulla C, Briffa K, Jones PD, Efthymiadis D, Brunetti M, Nanni T, Maugeri M, Mercalli L, Mestre O, Moisselin JM, Begert M, Müller-Westermeier G, Kveton V, Bochnicek O, Stastny P, Lapin M, Szalai S, Szentimrey T, Cegnar T, Dolinar M, Gajic-Capka M, Zaninovic K, Majstorovic Z, Nieplova E (2007) HISTALP - historical instrumental climatological surface time series of the Greater Alpine Region. Int J Climatol 27:17-46. https:// doi.org/10.1002/joc.1377

Auer I, Böhm R, Jurkovic A, Orlik A, Potzmann R, Schöner W, Ungersböck M, Brunetti M, Nanni T, Maugeri M, Briffa K, Jones P, Efthymiadis D, Mestre O, Moisselin JM, Begert M, Brazdil R, Bochnicek O, Cegnar T, Gajic-Capka M, Zaninivic K, Majstorovic Z, Szalai S, Szentimrey T (2005) A new instrumental precipitation dataset in the greater alpine region for the period 1800-2002. Int J Climatol 25:139-166. https://doi.org/10.1002/joc.1135

Bishop CM (1995) Neural networks for pattern recognition. Oxford University Press, Oxford

BlLkNÖ Blätter des Vereins für Landeskunde von Niederösterreich (1866) 2:56

Böhm R, Auer I, Schöner W, Ganekind M, Gruber C, Jurkovic A, Orlik A, Ungersböck M (2009) Eine neue Website mit instrumentellen Qualitäts-Klimadaten für den Großraum Alpen zurück bis 1760 . Wien Mitt 216:7-20

Böhm R, Auer I, Schöner W, Ungersböck M, Huhle C, Nanni T, Brunetti M, Maugeri M, Mercalli L, Gajic-Capka M, Zaninovic K, Szalai S, Szentimrey T, Cegnar T, Bochnicek O, Begert M, Mestre O, Moisselin JM, Müller-Westermeier G, Majstorovic Z (2003) Der Alpine Niederschlagsdipol-ein dominierendes Schwankungsmuster der Klimavariabilität in den Scales $100 \mathrm{~km}-$ 100 Jahre. Terra Nostra 6:61-65

Bradford BR (2000) Drought events in Europe. In: Vogt JV, Somma F (eds) Drought and drought mitigation in Europe. Kluwer, Dordrecht, pp 7-20

Brunetti M, Maugeri M, Nanni T, Auer I, Böhm R, Schöner W (2006) Precipitation variability and changes in the greater alpine region over the 1800-2003 period. J Geophys Res 111:D11107. https:// doi.org/10.1029/2005JD006674

Brunetti M, Lentini G, Maugeri M, Nanni T, Auer I, Böhm R, Schöner W (2009) Climate variability and change in the Greater Alpine Region over the last two centuries based on multi-variable analysis. Int $\mathrm{J}$ Climatol 29:2197-2225. https://doi.org/10.1002/joc.1857

Cai W, Zhang Y, Chen Q, Yao Y (2015) Spatial patterns and temporal variability of drought in Beijing-Tianjin-Hebei metropolitan areas in China. Adv Meteorol 289471:1-14. https://doi.org/10.1155/2015/ 289471 
Dai A (2011) Characteristics and trends in various forms of the Palmer Drought Severity Index during 1900-2008. J Geophys Res 116: D12115. https://doi.org/10.1029/2010JD015541

Efthymiadis D, Jones PD, Briffa KR, Auer I, Böhm R, Schöner W, Frei C, Schmidli J (2006) Construction of a 10-min-gridded precipitation data set for the Greater Alpine Region for 1800-2003. J Geophys Res 111:D01105. https://doi.org/10.1029/2005JD006120

García-Herrera R, Díaz J, Trigo RM, Luterbacher J, Fischer EM (2010) A review of the European summer heat wave of 2003. Crit Rev Environ Sci Technol 40:267-306. https://doi.org/10.1080/ 10643380802238137

Haslinger K, Koffler D, Schöner W, Laaha G (2014) Exploring the link between meteorological drought and streamflow: effects of climatecatchment interactions. Water Resour Res 50(3):2468-2487. https:// doi.org/10.1002/2013WR015051

Heim RR Jr (2002) A review of twentieth-century drought indices used in the United States. Bull Am Meteorol Soc 83(8):1149-1165. https:// doi.org/10.1175/1520-0477(2002)083<1149:AROTDI>2.3.CO;2

Hennig C (2007) Cluster-wise assessment of cluster stability. Comput Stat Data Anal 52:258-271

Hoerling M, Eischeid J, Perlwitz J, Quan X, Zhang T, Pegion P (2012) On the increased frequency of Mediterranean drought. J Clim 25(6): 2146-2161. https://doi.org/10.1175/JCLI-D-11-00296.1

Isotta FA, Frei C, Weilguni V, Perčec Tadić M, Lassègues P, Rudolf B, Pavan V, Cacciamani C, Antolini G, Ratto SM, Munari M, Micheletti S, Bonati V, Lussana C, Ronchi C, Panettieri E, Marigo G, Vertačnik G (2014) The climate of daily precipitation in the Alps: development and analysis of a high-resolution grid dataset from panAlpine rain-gauge data. Int J Climatol 34:1657-1675. https://doi. org/10.1002/joc.3794

Jenicek M, Seibert J, Zappa M, Staudinger M, Jonas T (2016) Importance of maximum snow accumulation for summer low flows in humid catchments. Hydrol Earth Syst Sci 20:859-874. https://doi.org/10. 5194/hess-20-859-2016

Jones PD, Hulme M (1996) Calculating regional climatic time series for temperature and precipitation: methods and illustrations. Int $\mathrm{J}$ Climatol 16(4):361-377. https://doi.org/10.1002/(SICI)10970088(199604)16:4<361::AID-JOC53>3.0.CO;2-F

Kaufman L, Rousseeuw PJ (2005) Finding groups in data: an introduction to cluster analysis. Wiley, Hoboken

Naresh Kumar M, Murthy CS, Sesha Sai MVR, Roy PS (2009) On the use of Standardized Precipitation Index (SPI) for drought intensity assessment. Meteorol Appl 16:381-389. https://doi.org/10.1002/ met.136

McKee TB, Doeskin NJ, Kleis J (1993) The relationship of drought frequency and duration to time scales. Preprints, $8^{\text {th }}$ Conf. on Applied Climatology Anaheim CA. Amer Meteor Soc 179-184

Mishra AK, Singh VP (2010) A review of drought concepts. J Hydrol 391:202-216. https://doi.org/10.1016/j.jhydrol.2010.07.012

Nester T, Kirnbauer R, Parajka J, Blöschl G (2012) Evaluating the snow component of a flood forecasting model. Hydrol Res 43:762-779. https://doi.org/10.2166/nh.2012.041

Palmer WC (1965) Meteorological drought. Tech Rep Weather Bur Res Pap 45, U.S. Dep of Commerce Washington D. C

Parajka J, Blöschl G (2008) The value of MODIS snow cover data in validating and calibrating conceptual hydrologic models. J Hydrol 358(3-4):240-258. https://doi.org/10.1016/j.jhydrol.2008.06.006

Parajka J, Blaschke AP, Blöschl G, Haslinger K, Hepp G, Laaha G, Schöner W, Trautvetter H, Viglione A, Zessner M (2016) Uncertainty contributions to low-flow projections in Austria. Hydrol Earth Syst Sci 20:2085-2101. https://doi.org/10.5194/hess20-2085-2016

Parry S, Hannaford J, Lloyd-Hughes B, Prudhomme C (2012) Multi-year droughts in Europe: analysis of development and causes. Hydrol Res 43(5):689-706. https://doi.org/10.2166/nh.2012.024
Patel NR, Chopa P, Dadhwal VK (2007) Analyzing spatial patterns of meteorological drought using standardized precipitation index. Meteorol Appl 14:329-336. https://doi.org/10.1002/met.33

Pekarova P, Miklanek P, Pekar J (2006) Long-term trends and runoff fluctuations of European rivers. Proceedings of the Fifth FRIEND World Conference on Climate Variability and ChangeHydrological Impacts. Havana Cuba. IAHS 308: 520-525

Rousseeuw PJ (1987) Silhouettes: a graphical aid to the interpretation and validation of cluster analysis. Comput Appl Math 20:53-65. https:// doi.org/10.1016/0377-0427(87)90125-7

Schwarb M (2000) The Alpine precipitation climate: evaluation of a highresolution analysis scheme using comprehensive rain-gauge data, Ph.D. Thesis, Swiss Fed. Inst. of Technol. (ETH), Zurich, Switzerland, 131pp

Sheffield J, Wood EF, Roderick ML (2012) Little change in global drought over the past 60 years. Nature 491:435-438. https://doi. org/10.1038/nature 11575

Sheffield J, Wood EF (2008) Global trends and variability in soil moisture and drought characteristics, 1950-2000, from observation-driven simulations of the terrestrial hydrologic cycle. J Clim 21:432-458. https://doi.org/10.1175/2007JCLI1822.1

Sheffield J, Wood EF (2007) Characteristics of global and regional drought, 1950-2000: analysis of soil moisture data from off-line simulation of the terrestrial hydrologic cycle. J Geophys Res 112: D17115. https://doi.org/10.1029/2006JD008288

Soja G, Züger J, Knoflacher M, Kinner P, Soja A-M (2013) Climate impacts on water balance of a shallow steppe lake in Eastern Austria (Lake Neusiedl). J Hydrol 480:115-124. https://doi.org/10. 1016/j.jhydrol.2012.12.013

Soulé PT (1990) Spatial patterns of multiple drought types in the contiguous United States: a seasonal comparison. Clim Res 1:13-21

Spinoni J, Naumann G, Vogt JV, Barbosa P (2015) The biggest drought events in Europe from 1950 to 2012. J Hydrol Reg Stud 3:509-524. https://doi.org/10.1016/j.ejrh.2015.01.001

Spinoni J, Naumann G, Carrao H, Barbosa P, Vogt JV (2014) World drought frequency, duration, and severity for 1951-2010. Int J Climatol 34(8):2792-2804. https://doi.org/10.1002/joc.3875

Spinoni J, Antofie T, Barbosa P, Bihari Z, Lakatos M, Szalai S, Szentimrey T, Vogt JV (2013) An overview of drought events in the Carpathian Region in 1961-2010. Adv Sci Res 10:21-32. https://doi.org/10.5194/asr-10-21-2013

Stagge JH, Kohn I, Tallaksen LM, Stahl K (2015) Modeling drought impact occurrence based on meteorological drought indices in Europe. J Hydrol 530:37-50. https://doi.org/10.1016/j.jhydrol. 2015.09.039

Svoboda M, Lecomte D, Hayes M, Heim R, Gleason K, Angel J, Rippey B, Tinker R, Palecki M, Stooksbury D, Miskus D, Stephens S (2002) The drought monitor. Bull Amer Meteor Soc 83(8):11811190

Trenberth KE, Dai A, van der Schrier G, Jones PD, Barichivich J, Briffa KR, Sheffield J (2014) Global warming and changes in drought. Nat Clim Chang 4(1):17-22. https://doi.org/10.1038/nclimate2067

Tsakiris G, Vangelis H (2005) Establishing a drought index incorporating evapotranspiration. Eur Water 9/10:3-11

van Lanen HAJ, Laaha G, Kingston DG, Gauster T, Ionita M, Vidal JP, Vlnas R, Tallaksen LM, Stahl K, Hannaford J, Delus C, Fendekova M, Mediero L, Prudhomme C, Rets E, Romanowicz RJ, Sébastien G, Wong WK, Adler M-J, Blauhut V, Caillouet L, Chelcea S, Frolova N, Gudmundsson L, Hanel M, Haslinger K, Kireeva M, Osuch M, Sauquet E, Stagge JH, van Loon AF (2016) Hydrology needed to manage droughts: the 2015 European case. Hydrol Process 30:3097-3104. https://doi.org/10.1002/hyp.10838

van der Schrier G, Briffa KR, Jones PD, Osborne TJ (2006) Summer moisture variability across Europe. J Clim 19:2818-2834. https:// doi.org/10.1175/JCLI3734.1 
van der Schrier G, Efthymiadis D, Briffa KR, Jones PD (2007) European Alpine moisture variability for 1800-2003. Int J Climatol 27:415427. https://doi.org/10.1002/joc.1411

van Loon AF (2015) Hydrological drought explained. WIREs Water 2: 359-392. https://doi.org/10.1002/wat2.1085

Vincente-Serrano SM, Beguería S, López-Moreno JI (2010) A multiscalar drought index sensitive to global warming: the standardized precipitation evapotranspiration index. J Clim 23:1696-1718. https://doi.org/10.1175/2009JCLI2909.1

Vincente-Serrano SM (2006) Differences in spatial patterns of drought on different time scales: an analysis of the Iberian Peninsula. Water Resour Manag 20:37-60. https://doi.org/10.1007/s11269-006-2974-8
Wells N, Goddard S, Hayes MJ (2004) A self-calibrating palmer drought severity index. J Clim 17:2335-2351. https://doi.org/10.1175/15200442(2004)017<2335:ASPDSI>2.0.CO;2

Wilhite DA, Glantz MH (1985) Understanding the drought phenomenon: the role of definitions. Drought Mitigation Center Faculty Publications. Paper 20

Wilks DS (2011) Statistical methods in the atmospheric sciences. Int Geophys:91, 3rd edition Academic Press Burlington Massachusetts

Zargar A, Sadiq R, Naser B, Khan FI (2011) A review of drought indices. Environ Rev 19:333-349. https://doi.org/10.1139/a11013 